\title{
When Technology Does More Harm than Good: Technostress in Missionary Contexts
}

Dunaetz, D. R. (2022) When technology does more harm than good: Technostress in missionary contexts. Journal of the Evangelical Missiological Society, 2(1) 112-128 Preprint for all posting. ems.org/index.php/home/article/download/38/ $23 / 122$

David R. Dunaetz (iD) https://orcid.org/0000-0003-0991-897X Azusa Pacific University

\begin{abstract}
Although computer-mediated communication has contributed to the missionary enterprise by making the transmission of information easier and more efficient, the negative consequences of technological innovation in communication need to be considered. Technostress is the psychological discomfort people feel when interacting with technology, such as the pressure to respond quickly to emails and text messages, to post regularly on social media, or to master and use a new app. Missionaries are prone to experience technostress and the accompanying detrimental effects on ministry and family. A review of the literature clarifies when missionaries are most likely to experience this phenomenon and what can be done to reduce the negative consequences.
\end{abstract}

\section{Keywords: Missiology, Technology, Missionary, Stress}

Today's missionaries have means of communication available to them that previous generations of missionaries could never have imagined. They have computers, smartphones, tablets, and countless apps which let them easily communicate with the people whom they serve, the home office, their supporting churches and individuals, their banks, government officials, 
providers of commercial services, and other missionaries. The speed and potential efficiency of communication between people in different places far exceed what was available in the past. Yet communication through modern electronic technology comes with a cost. This cost includes the financial cost of purchasing the necessary equipment and subscriptions and, under some circumstances, a social cost when compared to the richness of face-to-face communication, as well as a psychological cost due to the stress induced by the widespread use of electronic technology.

This stress has come to be known as technostress, a broad term describing the "negative impact on attitudes, thoughts, behaviors, or body physiology that is caused either directly or indirectly by technology" (Weil \& Rosen, 1997, p. 5). This phenomenon describes anything from social pressure to master a new social media to the pain of installing a new printer to tensions felt by parents when their teen is using a cell phone at an inappropriate time. It occurs anytime that technology causes a person to feel uncomfortable, especially because they are not sure of how to best respond. For missionaries, technostress can be a daily occurrence, whether it be a never-empty email inbox, the use of new social media in ministry, directives from the home office to use a new app, an untimely update of an app, or the difficulties that accompany a poorly worded or missent text message.

\section{Stress and the Missionary}

A missionary lifestyle has long been associated with stress (Foyle, 1987; Gish, 1983; Loss, 1983). Common sources of stress include adapting to a new culture (Oberg, 1960), the pressure to change the world (Hunter, 2010), living in highly urban areas (Dunaetz, 2013), guilt for having a higher standard of living than most others (Carter, 1999), and, as the apostle Paul said, "Besides everything else, I face daily the pressure of my concern for all the churches" ( 2 Cor. 11:28, NIV). This paper examines a relatively new source of stress, technology.

In terms of personal well-being, stress can be understood as a person's reaction to negative or potentially negative events (Lazarus \& Folkman, 1984). Stressors are events in one's environment which may be perceived as a threat. For missionaries, conversations in the local language may be a stressor. Will the missionary understand the conversation? Will 
he be able to respond appropriately? Will he lose face, and status, by saying something inappropriate? The degree of threat felt will vary by missionary and by situation. Missionaries at the beginning of their career might feel quite uncomfortable in a conversation whereas years later, the same type of conversation may present almost no threat now that they are fluent in the language. In Lazarus and Folman's (1984) model of stress, stress is viewed as the result of our assessment of a threat. More specifically, stress is the difference between our assessment of the potential danger of an event and our assessment of our ability to respond to the event appropriately. This can be expressed as follows:

Our assessment of potential danger - Our assessment of our ability to respond $=$ Stress

If the danger is seen high (e.g., we might permanently damage the relationship with someone important) and our ability to respond is seen as low (e.g., we have no idea what the culturally appropriate behavior is), we will experience high stress. If the danger is seen as low (e.g., we have the opportunity to greet an old friend whom we have not seen in years) and our ability to respond is seen as high (e.g., we will greet them in a culturally appropriate way and we have time available to get caught up on all that has passed over the years), the stress will be low or non-existent.

With this model, we can see how technology may be a source of stress. We have all had experiences where technology has wasted our time, prevented us from communicating effectively, or has distracted us from more important things. These are all potential dangers. If we know how to respond to such potential dangers, we will feel little stress. But if we are not sure of the appropriate way to respond, our level of stress may increase. For example, if a financial supporter misinterprets a missionary's Facebook post and writes a negative comment, the missionary may not know how to respond. In this case, the missionary will experience stress.

In terms of work responsibilities, stress can be viewed as the difference between job demands (what we believe we are supposed to be doing) and the resources that we have (Bakker et al., 2004; Salanova et al., 2013). These resources might be specifically work-related, such as financial support provided by churches and individuals and the training that one's 
mission provides to missionaries newly arrived on the field, or they may be personal resources, such as one's relationship with God or one's knowledge, skills, and resources. When the job demands exceed our resources, we experience stress which can eventually lead to burnout. So, to the degree that missionaries believe that they do not have the resources (physical, financial, spiritual, mental, emotional, cultural, or relational) necessary to do what their job demands, they will feel stress. This stress can lead to a lack of well-being, burnout, or attrition (Hay et al., 2007).

Stress may also be viewed from a perspective of good stress (eustress) and bad stress (distress), depending on the effect that it has on the individual (Le Fevre et al., 2003). When a person experiences little external motivation to achieve work-related goals, the person may put forth little effort to achieve them. However, if the person learns that the boss is watching, the person might feel a bit more stress and increase his or her effort to achieve the goals. This form of accountability is generally considered positive and can be considered eustress. However, a greater threat (such as being fired the next time a small mistake is made) may create too much stress, or distress; rather than increasing performance and efficiency, it might lower them. In this sense, technostress can be either eustress or distress depending on one's appraisal of the technology being used (Califf et al., 2020). Technology is considered a source of eustress by a missionary when it is appraised positively as helping to accomplish mission-related tasks (e.g., communicating by email rather than by postal systems). Technology can also be appraised negatively, becoming a source of distress, such as might be in the case of the mandatory use of poorly designed accounting software.

\section{Technology and The Importance of Relationships}

From a Christian point of view, it is hard to overstate the importance of good relationships. In the gospels, ethical behavior is characterized by humble service to others (Mark 10:42-45, John 13:1-17) and loving one another (John 13:34-15:17). The Sermon on the Mount (Matt. 5-7) describes primarily social behavior, focusing on both our relationship with God and the relationship with others. Paul's calls to live a Spirit-directed life are primarily commands focused on relationships (e.g., Rom. 12-15, 
Eph. 4-6). Humans are so social by nature (Aronson \& Aronson, 2018) that this may be considered part of what it means to be made in the image of God (Gen. 1:26-27).

Because relationships are so important from both a human and a divine point of view, we should evaluate technology and our use of technology in terms of its effect on relationships. If technology helps missionaries to better love and serve others, then its use is good; if it does not, then we have simply adopted high-tech resounding gongs and clanging symbols (I Cor. 13:1). Two questions may be asked when evaluating the use of technology to communicate (Weil \& Rosen, 1997): 1) Does the technology encourage the exchange of accurate information? And 2) Does the technology permit me to connect emotionally with a person?

The accurate exchange of information is essential because Jesus and the gospel are centered on truth (John 14:6). The inaccurate exchange of information can easily occur in computer-mediated communication. Often the messages exchanged are so brief and the time the recipient spends scrolling through them is so short, that the accurate exchange of information does not occur.

Emotional connection (an understanding of how the other is feeling and validation of those feelings) is essential because this is a primary characteristic of a healthy relationship. "Rejoice with those who rejoice, weep with those who weep" (Rom. 12:15, ESV). "Be kind to one another, tenderhearted, forgiving one another, as God in Christ forgave you" (Eph. 4:32, ESV). "Have unity of mind, sympathy, brotherly love, a tender heart, and a humble mind" (I Pet 3:8, ESV). In many situations, electronic communication does not permit such emotional connection and should be reconsidered. Whereas face-to-face communication provides many cues concerning the emotional content of a message, including tone of voice, volume, facial expressions, and gestures in addition to the words spoken, sharing of emotion in electronic communication is typically limited to text, emoticons, and gifs, media which are far less nuanced than in-person exchanges (Daft \& Lengel, 1984; Dunaetz, 2019; Dunaetz et al., 2015). Without the multitude of cues concerning emotional content, electronic communication is far more prone to miscommunication than face-to-face communication. 


\section{Technostress}

Technostress is a subject currently researched by many psychologists, computer scientists, and leadership researchers. According to Google Scholar, over 1000 papers were published in 2020 mentioning the subject. When researchers measure technostress, they generally collect information about the feelings people experience when they do not believe they can respond to technology in an appropriate way (Tarafdar et al., 2011). Such feelings vary immensely but include a compulsive need to be connected and online, feeling forced to respond immediately, feelings of being trapped into multitasking, the inability to concentrate on complex problems that would otherwise require analysis and creativity, a loss of work-life balance, and feelings of being continually interrupted. All of these feelings may be experienced by missionaries, depending on their self-expectations and the expectations of others.

Research has generally found five types of technostress that people experience in various situations (Tarafdar et al., 2020; Tarafdar et al., 2011). Some are much more common for missionaries than others.

Techno-Overload. Techno-overload occurs when one feels the pressure to work faster and accomplish more tasks due to technology. Suppose a missionary starts a YouTube channel and many people each day start posting comments on the videos. To maximize the opportunity to share the gospel, the missionary may feel the need to respond to each comment, although he may never meet any of the people who follow him and correspond with him. Such pressure is an example of techno-overload. Other missionary examples of techno-overload may concern requirements set by the home office of the mission or by supporting churches. These requirements might involve the use of complex accounting and reporting apps or frequent reports of missionary activity to maintain financial support (cf. Nehrbass \& Dunaetz, 2018). Even a simple sermon by a pastor of a small church on encouraging missionaries might trigger a dozen emails that may feel overwhelming to a missionary because of the need to respond personally to each one.

Techno-Invasion. When technology makes us able to be reached anywhere and at any time so that we feel we cannot escape work, technoinvasion occurs. For some people, this blurring of work and personal time 
can be distressing. A lack of work-life balance (Guest, 2002) leads to exhaustion and burnout. Missionaries who work among resistant people groups (Woodberry, 1998) may be especially prone to this. Fruitful acts of ministry may be few and far between, so missionaries may feel the need to be continually available to those whom they serve so as to not miss any opportunities. Such missionaries might feel the need to be accessible 24 hours per day, never separated from their phone or computer.

Techno-Complexity. When a significant portion of a person's time is spent learning new technology, to such a degree that it reduces (rather than increases) the work that the person accomplishes, techno-complexity is experienced. Typically, a feeling of being intimidated by technology or a lack of mastery of the technology motivates someone to invest an inordinate amount of time in learning how to use it (Tarafdar et al., 2011). However, a desire to avoid work or other stressful situations may also push people towards pouring themselves into mastering complex technological devices and software. This may especially be the case for missionaries. Success in mastering complex forms of technology may be easier to achieve than success in evangelism and church planting; this may motivate the missionary to spend his or her time where success comes relatively easily, even though little may be accomplished which contributes to achieving the missionary's long-term goals.

Techno-Insecurity. People experience techno-insecurity when they believe that their job or social position is threatened by technology. They may fear losing their job because technology can replace them or because a person more at ease with technology (typically a younger person) could do their job better. Often, people experiencing techno-insecurity become cynical about the technology, refusing to recognize its potential value; this may be an ego-protective measure (Tesser, 1988) to help them feel better about themselves. Missionaries may not feel that their job is threatened by new technology, but the thought of leaving their mission and returning to their home country may be threatening because they no longer have the currently required technological skills to enter the job market; this would especially be true of missionaries who had a promising career before going into missions, but it is not unlike what stay-at-home mothers experience when they go back into the workforce. 
Techno-Uncertainty. The stress that comes from the inconvenience associated with bugs, changes, and upgrades in technology is known as techno-uncertainty. One may have to face a software upgrade with no warning or run into a bug at a crucial moment. This may be as simple as a change of interface in a social media, or a system crash that causes a loss of files. The previous knowledge and mastery of the technology may become useless, and more time must be invested into learning how to use it or figuring out how to respond. Missionaries may be especially prone to this type of technostress when they are experiencing other sources of stress; a change of software may be another annoyance that pushes them further into frustration.

Techno-Comparison. An additional source of technostress, besides the traditionally defined five types (Tarafdar et al., 2007) described above comes from comparing oneself to other users of a technology, technocomparison. When users, typically of social media, compare their lives with those of others who post on the platform, they may become discouraged due to the successes and idealistic lifestyles portrayed in what they view compared to their own lives. When we compare ourselves to people who appear to be superior to us, we often feel discouraged and our self-esteem goes down (Collins, 1996). Such social comparison appears to be the prime driver of the increase in depression that has been observed in Generation $\mathrm{Z}$ (Heffer et al., 2019; Twenge, 2014, 2017). Missionaries might compare themselves to other missionaries who portray themselves as more successful or they may compare themselves to friends and family in their home country who quite likely have a higher material standard of living. Such comparisons are likely to have a negative effect and trigger various self-protective mechanisms such as avoiding others or devaluing what others have or do (Hogg, 2006; Tesser, 1988).

\section{Susceptibility to Technostress}

Certain organizational conditions, personal characteristics, and demographics make some individuals more susceptible to technostress than others. By recognizing these conditions and characteristics, missionaries may be better equipped to reduce or prevent technostress 
from occurring in their specific situation, for both themselves and those for whom they are responsible.

\section{Organizational Conditions Leading to Technostress}

Several aspects of a mission organization's culture can contribute to technostress. Organizations, or specific leaders, which expect missionaries to respond immediately to emails or texts will have missionaries with higher levels of technostress than those who are more flexible (Ayyagari et al., 2011). The need to respond immediately to electronic communication creates work-home conflict, work overload, and feelings of being violated. It also creates role ambiguity when the missionaries do not know what their proper role is at the moment. Should they be responsible missionaries and continue what they were doing and what they had planned to do? Or should they be responsive missionaries and change priorities by replying quickly to the electronic communication?

Similarly, people feel higher levels of technostress in centralized, hierarchical organizations rather than in flatter organizations where people have more freedom to decide what to do (Wang et al., 2008). Many missionaries assume that they, as professionals with little direct supervision, are working in organizations that trust them to make the best decisions in a given context. However, there is a tendency, especially among older missionaries, to view missionary work as very hierarchical. Thomas Hale (1995) argues that for missionaries to be team players, "that the team members submit to their leader, regardless of his qualities" (p. 219) and that the purpose of authority is to "mediate God's will in the Christian community" (p. 231) so "if one has a problem submitting to authority, his problem is basically with God" (p. 231). This view of organizational structure may not only promote technostress if the leaders require immediate responses, but this view also sets the stage for conflicts that are expected to be resolved through submission (in contrast to cooperation), an approach to conflict management that makes missionary attrition more likely (Dunaetz, 2016; Dunaetz \& Greenham, 2018).

\section{Personal Characteristics and Susceptibility to Technostress}

Studies have found several characteristics of individuals that appear to make them more or less prone to technostress. 
Sex. In work contexts, men tend to have higher levels of technostress than women (Tarafdar et al., 2011). Although men are more willing to try new technologies than women (who tend to try new technologies only when there is a felt need), they get more frustrated and experience more discomfort due to technology. In contrast, computer confidence is a good predictor of lower technostress (Tarafdar et al., 2011). Those who believe they are competent in the use of computer technology typically experience less technostress than those who believe they are less competent.

Age. Older people tend to experience less technostress than younger people (Tarafdar et al., 2011). While this seems counter-intuitive because many older people struggle with learning new technology, they most likely experience less technostress because they handle stressful situations better than younger people (Aldwin, 1991). In addition to being able to put stressful situations into perspective because of their maturity, they tend to have more power in organizations, have more control over what technologies they choose to use, and are better able to judge how important it is to learn a technology.

Smartphone Compulsiveness. One of the best predictors of technostress is smartphone compulsiveness (Lee et al., 2014). Smartphone compulsiveness is characterized by the continual use of the smartphone and a feeling that one does not have personal control over one's use of the smartphone. Not only may a smartphone be used to exchange information, but also for the relief of boredom and entertainment. People who are high in smartphone compulsiveness tend to have an external locus of control (i.e., a belief that their behaviors are primarily influenced by forces exterior themselves; Hiroto, 1974) in contrast to an interior locus of control (a belief that they themselves are primarily responsible for their behavior). They also tend to be high in materialism (placing a high value on material things) and high in social interaction anxiety. Interestingly, they also tend to be high in the need for touch (the need to receive sensory information through the haptic system; Peck \& Childers, 2003), for example, the need to touch something before buying it in the supermarket. The compulsive use of the cellphone (for texting or social media) seems to be due to the immediate feedback that it provides. This creates a sort of addiction that interferes in other areas of one's life, which in turn increases one's level of stress. 
Social Media Use. Facebook, Twitter, Instagram, and other social media seem to be a unique source of technostress (Tarafdar et al., 2020). Social media sites like Facebook have an extremely rich variety of content. The user may exchange messages with other users, post pictures or announcements, respond to others' posts, play games, look at photos, search for people from one's past, read others' newsfeeds, watch and read news from other sources, participate in affinity groups, or watch interesting videos (e.g., pets acting like humans). People have a natural tendency to prioritize clicking on that which makes them angry or afraid. The anger and fear thus created raise the level of stress that one feels. When one is sufficiently distressed, the need for some sort of diversion is felt. Rather than leave the social media site (for example, by leaving the computer or by putting the phone down), people often find it easier to distract themselves on the social media site itself (e.g., stop reading about their political outgroup and start watching cute cat videos). This creates an addictive cycle alternating between stress and diversion that can occupy a major portion of an individual's time. Unlike other sources of technostress which cause people to want to avoid the technology, social media sites create an addiction and dependence which causes the user to seek it out.

\section{Consequences of Technostress}

Although technostress is rarely at the forefront of a missionary's life, research has demonstrated that it has several important negative consequences that we should be aware of (Ragu-Nathan et al., 2008; Tarafdar et al., 2015; Tarafdar et al., 2007; Tarafdar et al., 2011). The first consequence, and perhaps the most acutely felt, is role overload, the feeling that one has too much to do and not enough time to do it (Coverman, 1989). In addition to mastering a new language and culture, ministering to the needs of people around them, and changing the world for Christ, missionaries may feel they have to respond to a never-ending stream of texts and emails, as well as maintain several social media sites. This can lead to burnout and missionary attrition.

Techno-stress also contributes to role conflict, the feelings that one has when facing contradictory expectations and requirements (Rizzo et al., 1970). Missionaries may feel role conflict when they sense different 
expectations from various stakeholders. Supporters may expect frequent communication with them; field leadership may expect a commitment to maintaining the existing programs and ministries; local Christians may have expectations for pastoral care; missionaries may have selfexpectations for effective ministry to the least reached. It may not be possible to accomplish all these things, a problem compounded by continual electronic communication with the various stakeholders.

In terms of the missionary's future ministry, technostress contributes to both lower organizational commitment, higher turnover intentions, and lower job satisfaction (Ragu-Nathan et al., 2008). Because of the discomfort associated with continual stress, the feelings towards one's organizational context become less positive and the frequency of leaving the field may increase. Technostress has also been shown to decrease innovation: techno-overload causes a person to have less time and energy for deep-processing of ideas or generating new ones, while technocomplexity prevents mastery of complex technology which could otherwise be used to innovate (Tarafdar et al., 2011).

Although the goal of using technology is typically to increase productivity and efficiency, it can sometimes lead to a decrease (Tarafdar et al., 2010). When techno-complexity is high, a missionary may spend an inordinate amount of time trying to figure out how to use the technology, leaving less time for ministry. Techno-uncertainty may consume much of the missionary's time as he or she learns to use updates or troubleshoot the various problems that occur with the technology. Techno-overload may cause a missionary to waste time going through large amounts of irrelevant information, perhaps becoming distracted and losing time going down various rabbit holes that grab his or her attention.

\section{Strategies for Reducing Technostress}

There are several strategies that missionaries and mission leaders can use for reducing technostress (Tarafdar et al., 2010; Tarafdar et al., 2011; Weil \& Rosen, 1997).

\section{Individual Strategies}

At the individual level, limiting one's use of social media might be the change that can reap the greatest rewards. The addictive nature of social 
media means that we often pull away from it only after we realize how much time we have wasted. A useful experiment is to leave social media for a week to discover how much one loses and gains. It is possible that little true ministry occurs by collecting likes, giving likes, or staying up to date on friends' pets or political views.

It may also help missionaries to personally evaluate how well different technologies contribute to the value of their communication with others. The value of the communication depends on the accuracy of the information transmitted and the emotional connection that occurs. Emotional connection enables a relationship to develop by increasing the level of trust and enabling one to better respond to the other person's needs. If some technologies do not contribute to sharing information accurately, developing trust, or enabling a better response to others' needs, a missionary may consider removing them from his or her life.

One way to analyze the appropriateness of a media for communication is through its richness (Daft \& Lengel, 1984). Media richness is the number of cues that are transmitted in an act of communication. In general, the richer the media, the more likely it is that information will be communicated accurately and that people will connect emotionally. Face-to-face communication is the richest. Texting and email would be far lower in media richness, and phone calls and video conferences would be somewhere in-between. Publicly communicating via social media might be the lowest of all given the ease of miscommunication. The value of a specific technology will depend on the individual and the context. People who are extraverted, people who are agreeable, and males tend to have a greater preference for communicating with rich media than do people who are introverted, people who are less agreeable, and females (Dunaetz et al., 2015). Extraversion and agreeableness motivate people to prefer rich media because of the pleasure and satisfaction that they receive from more direct communication. Males have a higher preference for rich communication apparently because they are less gifted than females in understanding the nuances communicated through less rich means of communication such as texting. 


\section{Organizational Strategies}

On an organizational level, mission organizations need to ensure that missionaries are adequately trained to use the software required by the organization. This includes adequate documentation and technical support which is responsive and easily reached. The training needs to clearly communicate the advantages of using the new technology so that the missionary is motivated to use it. An accurate description of the changes in a missionary's work that will be needed will make the arguments more convincing. Demonstrating the rewards of using a new technology before it is mandatory will make missionaries want to adopt it.

An organizational culture that encourages innovation and allows for failure will tend to lower technostress (Tarafdar et al., 2010). This will encourage missionaries to explore different technologies without being pressured to adopt the technologies which do not lead to greater efficiencies. Similarly, encouraging missionaries to provide support and information sharing with each other concerning ministry-related technology can lower technostress. People can feel support by receiving the information they need to overcome the technology-related problems they are experiencing and by evaluating in small groups what is important for ministry. For example, a discussion on the use of technology can be added regularly to the agenda of missionary team or field meetings.

In a sense, the essence of missionary work is communication. The Great Commission is essentially a charge to communicate the gospel to others and explain all that it entails in one's life. Modern electronics may either help or hinder this communication. In order to avoid unnecessary and destructive technostress, missionaries and mission leaders need to act wisely to ensure the well-being of a community of people who are giving their all for the furtherance of the gospel.

\section{References}

Aldwin, C. M. (1991). Does age affect the stress and coping process? Implications of age differences in perceived control. Journal of Gerontology, 46(4), 174-180.

Aronson, E., \& Aronson, J. (2018). The social animal (12th ed.). Worth Publishers. Ayyagari, R., Grover, V., \& Purvis, R. (2011). Technostress: Technological antecedents and implications. MIS Quarterly, 831-858. 
Bakker, A. B., Demerouti, E., \& Verbeke, W. (2004). Using the job demands-resources model to predict burnout and performance. Human Resource Management Review, 43(1), 83-104.

Califf, C. B., Sarker, S., \& Sarker, S. (2020). The bright and dark sides of technostress: A mixed-methods study involving healthcare IT. MIS Quarterly, 44(2), 809-856.

Carter, J. (1999). Missionary stressors and implications for care. Journal of Psychology and Theology, 27, 171-180.

Collins, R. L. (1996). For better or worse: The impact of upward social comparison on self-evaluations. Psychological Bulletin, 119(1), 51-69.

Coverman, S. (1989). Role overload, role conflict, and stress: Addressing consequences of multiple role demands. Social Forces, 67(4), 965-982.

Daft, R. L., \& Lengel, R. H. (1984). Information richness. A new approach to managerial behavior and organization design. Research in Organizational Behavior, 6(2), 191-233.

Dunaetz, D. R. (2013). Finding still waters and green pastures: Understanding and reducing stress in urban church planting. Great Commission Research Journal, 4, 235-250.

Dunaetz, D. R. (2016). Submission or cooperation? Two competing approaches to conflict management in mission organizations. In R. Cathcart Scheuermann \& E. L. Smither (Eds.), Controversies in mission: Theology, people, and practice in the 21st century (pp. 121-142). William Carey Library.

Dunaetz, D. R. (2019). Evangelism, social media, and the mum effect. Evangelical Review of Theology, 43(2), 138-151.

Dunaetz, D. R., \& Greenham, A. (2018). Power or concerns: Contrasting perspectives on missionary conflict. Missiology: An International Review, 46(1), 67-85.

Dunaetz, D. R., Lisk, T. C., \& Shin, M. (2015). Personality, gender, and age as predictors of media richness preference. Advances in Multimedia, 2015(243980), 1-9.

Foyle, M. F. (1987). Overcoming missionary stress. Evangelical Missions Information Service.

Gish, D. J. (1983). Sources of missionary stress. Journal of Psychology and Theology, 11(3), 231-236.

Guest, D. E. (2002). Perspectives on the study of work-life balance. Social Science Information, 41(2), 255-279.

Hale, T. (1995). On being a missionary. William Carey Library.

Hay, R., Lim, V., Blocher, D., Ketelaar, J., \& Hay, S. (2007). Worth keeping: Global perspectives on best practice in missionary retention. William Carey Library.

Heffer, T., Good, M., Daly, O., MacDonell, E., \& Willoughby, T. (2019). The longitudinal association between social-media use and depressive symptoms among adolescents and young adults: An empirical reply to Twenge et al. (2018). Clinical Psychological Science, 7(3), 462-470. 
Hiroto, D. S. (1974). Locus of control and learned helplessness. Journal of experimental psychology, 102(2), 187-193.

Hogg, M. A. (2006). Social identity theory. In P. J. Burke (Ed.), Contemporary social psychological theories (pp. 111-136). Stanford University Press.

Hunter, J. D. (2010). To change the world: The irony, tragedy, and possibility of Christianity in the late modern world. Oxford University Press.

Lazarus, R. S., \& Folkman, S. (1984). Stress, appraisal, and coping. Springer Publishing Company.

Le Fevre, M., Matheny, J., \& Kolt, G. S. (2003). Eustress, distress, and interpretation in occupational stress. Journal of Managerial Psychology.

Lee, Y.-K., Chang, C.-T., Lin, Y., \& Cheng, Z.-H. (2014). The dark side of smartphone usage: Psychological traits, compulsive behavior and technostress. Computers in Human Behavior, 31, 373-383.

Loss, M. (1983). Culture shock: Dealing with stress in cross-cultural living. Light and Life Press.

Nehrbass, K., \& Dunaetz, D. R. (2018). A multiple motives theory of church and missionary relationships. Missiology, 46(4), 388-406.

Oberg, K. (1960). Culture shock: Adjustment to new cultural environments. Practical Anthropology, 7, 177-182.

Peck, J., \& Childers, T. L. (2003). Individual differences in haptic information processing: The "need for touch" scale. Journal of Consumer Research, $30(3)$, 430-442.

Ragu-Nathan, T. S., Tarafdar, M., Ragu-Nathan, B. S., \& Tu, Q. (2008). The consequences of technostress for end users in organizations: Conceptual development and empirical validation. Information Systems Research, 19(4), 417-433.

Rizzo, J. R., House, R. J., \& Lirtzman, S. I. (1970). Role conflict and ambiguity in complex organizations. Administrative Science Quarterly, 150-163.

Salanova, M., Llorens, S., \& Cifre, E. (2013). The dark side of technologies: Technostress among users of information and communication technologies. International Journal of Psychology, 48(3), 422-436.

Tarafdar, M., Maier, C., Laumer, S., \& Weitzel, T. (2020). Explaining the link between technostress and technology addiction for social networking sites: A study of distraction as a coping behavior. information Systems Journal, 3o(1), 96-124.

Tarafdar, M., Pullins, E. B., \& Ragu-Nathan, T. S. (2015). Technostress: Negative effect on performance and possible mitigations. information Systems Journal, 25(2), 103-132.

Tarafdar, M., Tu, Q., Ragu-Nathan, B. S., \& Ragu-Nathan, T. S. (2007). The impact of technostress on role stress and productivity. Journal of Management Information Systems, 24(1), 301-328. 
Tarafdar, M., Tu, Q., \& Ragu-Nathan, T. S. (2010). Impact of technostress on end-user satisfaction and performance. Journal of Management Information Systems, 27(3), 303-334.

Tarafdar, M., Tu, Q., Ragu-Nathan, T. S., \& Ragu-Nathan, B. S. (2011). Crossing to the dark side: Examining creators, outcomes, and inhibitors of technostress. Communications of the Association for Computing Machinery, 54(9), 113-120.

Tesser, A. (1988). Toward a self-evaluation maintenance model of social behavior. In L. Berkowitz (Ed.), Advances in experimental social psychology (Vol. 21, pp. 181227). Academic Press.

Twenge, J. M. (2014). Generation me: Why today's young Americans are more confident, assertive, entitled--and more miserable than ever before (Rev. ed.). Atria.

Twenge, J. M. (2017). Have smartphones destroyed a generation? The Atlantic. https://www.theatlantic.com/magazine/archive/2017/o9/has-the-smartphonedestroyed-a-generation/534198/

Wang, K., Shu, Q., \& Tu, Q. (2008). Technostress under different organizational environments: An empirical investigation. Computers in Human Behavior, 24(6), 3002-3013.

Weil, M. M., \& Rosen, L. D. (1997). Technostress: Coping with technology @work @home @play. J. Wiley \& Sons.

Woodberry, J. D. (Ed.). (1998). Reaching the resistant: Barriers and bridges for mission. William Carey Library.

About the Author

David R. Dunaetz (PhD Claremont Graduate University) is Associate Professor in the

Department of Leadership and Organizational Psychology, Azusa Pacific University. 